\title{
The effects of hourly differences in air pollution on the risk of myocardial infarction: case crossover analysis of the MINAP database
}

\author{
(c) $(1)$ (8)
}

\begin{abstract}
Krishnan Bhaskaran lecturer in statistical epidemiology, Shakoor Hajat senior lecturer in epidemiology and medical statistics, Ben Armstrong professor of epidemiological statistics, Andy Haines professor of public health and primary care, Emily Herrett research degree student, Paul Wilkinson reader in environmental epidemiology, Liam Smeeth professor of clinical epidemiology
\end{abstract}

London School of Hygiene and Tropical Medicine, London, UK

\begin{abstract}
Objectives To investigate associations between air pollution levels and myocardial infarction (MI) on short timescales, with data at an hourly temporal resolution.

Design Time stratified case crossover study linking clinical data from the Myocardial Ischaemia National Audit Project (MINAP) with $\mathrm{PM}_{10}$, ozone, $\mathrm{CO}, \mathrm{NO}_{2}$, and $\mathrm{SO}_{2}$ data from the UK National Air Quality Archive. Pollution effects were investigated with delays (lags) of 1-6, 7-12, 13-18, 19-24, and 25-72 hours in both single and multi-pollutant models, adjusted for ambient temperature, relative humidity, circulating levels of influenza and respiratory syncytial virus, day of week, holidays, and residual seasonality within calendar month strata.
\end{abstract}

Setting Population based study in 15 conurbations in England and Wales.

Subjects 79288 diagnoses of myocardial infarction recorded over the period 2003-6.

Main outcome measures Excess risk of myocardial infarction per 10 $\mu \mathrm{g} / \mathrm{m}^{3}$ increase in pollutant level.

Results In single pollutant models, $\mathrm{PM}_{10}$ and $\mathrm{NO}_{2}$ levels were associated with a very short term increase in risk of myocardial infarction 1-6 hours later (excess risks $1.2 \%$ (95\% confidence interval 0.3 to 2.1 ) and $1.1 \%$ ( 0.3 to 1.8 ) respectively per $10 \mu \mathrm{g} / \mathrm{m}^{3}$ increase); the effects persisted in multi-pollutant models, though with only weak evidence of an independent $\mathrm{PM}_{10}$ effect $(\mathrm{P}=0.05)$. The immediate risk increases were followed by reductions in risk at longer lags: we found no evidence of any net excess risk associated with the five pollutants studied over a 72 hour period after exposure.

Conclusions Higher levels of $\mathrm{PM}_{10}$ and $\mathrm{NO}_{2}$, which are typically markers of traffic related pollution, seem to be associated with transiently increased risk of myocardial infarction 1-6 hours after exposure, but later reductions in risk suggest that air pollution may be associated with bringing events forward in time ("short-term displacement") rather than increasing overall risk. The well established effect of air pollution on cardiorespiratory mortality may not be mediated through increasing the acute risk of myocardial infarction, but through another mechanism.

\section{Introduction}

Several studies have shown short term associations between common environmental pollutants and overall mortality ${ }^{1-5}$ and cardiovascular mortality, ${ }^{6}{ }^{7}$ but a recent systematic review suggested that the associations between pollution levels and myocardial infarction specifically are less clear, with less than half of the studies identified finding evidence of any detrimental effect of particles with diameter $<10 \mu \mathrm{m}\left(\mathrm{PM}_{10}\right)$, ozone, carbon monoxide $(\mathrm{CO})$, nitrogen dioxide $\left(\mathrm{NO}_{2}\right)$, or sulphur dioxide $\left(\mathrm{SO}_{2}\right){ }^{8}$

Most studies to date have investigated associations on a daily time scale (often referred to as "short term"), but a small number of studies using data at a finer temporal resolution have observed effects on risk of myocardial infarction within a few hours of exposure to particulate matter ${ }^{9}{ }^{10}$ and more generally to traffic. ${ }^{11}$ A recent experimental study showing ischaemic and thrombotic effects within a few hours of controlled exposure to dilute diesel exhaust fumes also highlights the possibility of very short term (<1 day) clinical effects. ${ }^{12}$

Our aim was to quantify the association at an hourly temporal resolution between risk of myocardial infarction and exposure to $\mathrm{PM}_{10}$, ozone, $\mathrm{CO}, \mathrm{NO}_{2}$, and $\mathrm{SO}_{2}$, making use of a large database of myocardial infarction events in England and Wales 
that records accurate time of event, and within which the validity of events could be confirmed against electrocardiographic and laboratory marker data.

\section{Methods \\ Clinical data}

The Myocardial Ischaemia National Audit Project (MINAP) is a national register recording all hospital admissions for myocardial infarction and other acute coronary syndromes, with participation from all hospitals in England and Wales that admit patients with these conditions (details in web appendix on bmj.com). We included all events with a discharge diagnosis of ST elevation myocardial infarction (that is, myocardial infarction with elevation of the ST electrocardiograph segment), non-ST elevation myocardial infarction, or troponin positive acute coronary syndrome and with the time of the event available occurring among patients residing within one of 15 conurbations in England and Wales (Greater London, West Midlands, Greater Manchester, West Yorkshire, Tyneside, Liverpool, Nottingham, Sheffield, Bristol, Leicester, Potteries, Cardiff, Southampton, Kingston upon Hull, and Norwich (conurbation boundaries pre-defined to match earlier work $\left.^{13}\right)$ ) during the period 2003-6. Timing data may be recorded in MINAP at several points during the course of an event. When it was recorded, we used the time of symptom onset as the time of the event. When this was not available, we used one of the following time fields (in order of preference): first call for help, arrival of first professional, arrival of emergency services, arrival at hospital, reperfusion, cardiac arrest.

\section{Data on pollution, ambient temperature, and infectious disease levels}

For each of the 15 conurbations, we obtained hourly levels of $\mathrm{PM}_{10}$, ozone, $\mathrm{CO}, \mathrm{NO}_{2}$, and $\mathrm{SO}_{2}$ by retrieving data from urban background monitoring stations from the UK Air Quality Data and Statistics Database For the five conurbations with more than one monitoring station, data were combined into a single hourly series using the AIRGENE algorithm. ${ }^{14}$

Daily mean temperature (approximated as the mean of daily minimum and maximum temperatures) and relative humidity (derived from 9 am and $3 \mathrm{pm}$ dewpoint and temperature) were obtained from weather monitoring stations within the 15 conurbations via the British Atmospheric Data Centre (UK Meteorological Office MIDAS Land Surface Stations Data). After again combining multiple station data within conurbations using the AIRGENE algorithm, ${ }^{14}$ we found daily temperature was available for 17 106/21 915 conurbation days (78\%). Data for the remaining days were imputed using 10 complete temperature series that were available at a broader "regional" level (further details in web appendix).

As a measure of level of circulating viral infections, we obtained daily counts of laboratory confirmed cases of influenza A and respiratory syncytial virus for each of $10 \mathrm{UK}$ regions from the Communicable Diseases Surveillance Centre at the Health Protection Agency.

\section{Statistical methods}

We performed a fixed stratum, case crossover analysis. ${ }^{15}$ A case crossover study can be thought of as a type of self matched, case control study: for each individual, exposure data are collected for the "case" day (that is, the day of the myocardial infarction) and a set of "control" days that were not associated with the event of interest. In the fixed stratum design, externally fixed time strata are used as the source of control days, a feature which ensures the validity of standard analytical methods. ${ }^{16}$ In our study the fixed strata were calendar months, and the control days comprised every other day in the calendar month of the myocardial infarction. Exposure and confounder data were obtained at the hour of the myocardial infarction event for both case and control days; matching case and control data on time of day in this way avoids confounding due to any natural circadian patterns in myocardial infarction risk.

Conditional logistic regression was then used to compare exposure data on case and control days. The study design automatically controls for time-invariant individual level confounders, because comparisons are made within individuals. For location-specific data, including pollution levels, we used the patient's place of residence as the location, thus our assumption was that the myocardial infarction occurred in the same conurbation as the patient's home. We adjusted for potential time-varying confounders: daily mean temperature (five linear terms representing the average of lag days $0-1,2-7$, $8-14,15-21,22-28$, based on previously observed associations between temperature and myocardial infarction ${ }^{17}$ ); daily relative humidity (average of the current and previous three days, as a 4 degrees of freedom cubic spline to allow for non-linearity), daily levels of influenza and respiratory syncytial virus (each in three categories representing 0,1 , or $\geq 2$ laboratory confirmed cases in the conurbation in question); day of week; and holidays. We allowed for any residual seasonality within calendar months by including a single harmonic Fourier series. ${ }^{18}$

To aid presentation and interpretation, we converted the odds ratios from the conditional logistic regression models into excess risks: these represent the percentage change in risk of myocardial infarction associated with a given increase in pollution level, and are approximated by $100 \times($ odds ratio- 1 ).

In order to cover the time period in which pollution effects on myocardial infarction have been observed in previous studies, ${ }^{8}$ we modelled each pollutant using five linear distributed lag terms covering a 72 hour lag period, specifically the average of $1-6,7-12,13-18,19-24$, and 25-72 hours. Lag periods for the control days were calculated based on the time of day at which the case myocardial infarction occurred. These periods were chosen as a compromise between flexibility and model parsimony. The cumulative effect (over 72 hours) of a change in pollution was calculated by summing the five parameter estimates on the log scale. ${ }^{19}$ The primary analysis used separate models for each pollutant, and we compared our results with those from a multi-pollutant model including all five pollutants. We also explored two-pollutant models to shed further light on changes between the two sets of effect estimates.

\section{Effect modifiers and the role of season and hourly temperature}

Three further exploratory analyses were performed. First, we examined effect modification by age, prior coronary heart disease, and smoking status by fitting interaction terms in the single pollutant models. Wald tests were carried out on the interaction terms, and, to allow for multiple testing (15 tests in total covering three effect modifiers and five pollutants), we considered only $\mathrm{P}$ values $<0.003$ as providing good evidence of effect modification (for a family-wise significance level of $0.05)$.

Second, since correlations between pollutants varied by season and followed a different pattern in summer (defined as June-August), we explored the interaction between season (summer $v$ other seasons) and pollution effects. 
Third, we investigated the effect of controlling for ambient temperature in our models at an hourly rather than daily resolution (restricting to the $9 / 15$ conurbations with hourly temperature data: Bristol, Cardiff, Greater London, Greater Manchester, Liverpool, Nottingham, Sheffield, West Midlands, and West Yorkshire). As with pollution, hourly temperature was parameterised as five linear terms covering lag periods $1-6$, $7-12,13-18,19-24$, and $25-72$ hours.

\section{Sensitivity analyses}

Several sensitivity analyses were performed, involving changes to the original single pollutant models, to check the robustness of our main findings to key aspects of study design and model specification. First, we restricted the study population to those with a recorded time of symptom onset, thus excluding the $26 \%$ of events for which the event time was drawn from other variables. Second, we restricted the study population to those patients whose diagnosis of myocardial infarction could be confirmed by at least one recorded corroborative electrocardiogram (for ST elevation myocardial infarction) or raised troponin or creatine kinase levels. Third, we repeated our main analysis using robust standard errors to allow for any possible clustering by conurbation. Fourth, to assess the impact of choice of time strata, we analysed the data using 14 day (rather than calendar month) time strata to define case and control days. Fifth, returning to calendar month strata, to reduce potential autocorrelation in exposure data, we matched case and control days on day of the week, thus introducing gaps of at least seven days between case and control days. Finally, we used four-knot cubic splines in place of linear terms to control for temperature, to allow for any non-linear temperature effects.

\section{Results}

A total of 79288 myocardial infarctions with time of event available were recorded in MINAP within the 15 conurbations during 2003-6 (table $1 \Downarrow$ ). Overall, 34566 (44\%) of the events were ST elevation myocardial infarctions, though the proportion was notably higher in Kingston-upon-Hull. Time of myocardial infarction was most commonly based on the time of symptom onset $(n=58594,74 \%)$, time of call for help $(n=6887,9 \%)$, or time of arrival at hospital $(n=13144,17 \%)$. Of the 79288 events, $70331(89 \%)$ were confirmed by at least one recorded electrocardiogram (for ST elevation myocardial infarction) or raised troponin or creatine kinase levels.

Table $1 \Downarrow$ shows the median hourly pollution levels overall and within conurbations. We excluded 4931 events $(6.2 \%)$ from the multi-pollutant model because of missing pollution data; for single pollutant models, the number of events excluded ranged from $1952(2.5 \%)$ to 2447 (3.1\%) depending on the pollutant (further details in web appendix). Correlations between pollutant pairs were positive with the exception of ozone, which was negatively correlated with other pollutants. Correlations were weaker in summer $(r<0.5$ in all cases) compared with other seasons (table $2 \Downarrow$ ).

\section{Effects of pollutants on myocardial infarction risk in single and multi-pollutant models}

When the five pollutants under investigation were modelled in separate single pollutant models, there was evidence at the shortest lag term (1-6 hours) of a raised risk of myocardial infarction associated with higher $\mathrm{PM}_{10}$ and $\mathrm{NO}_{2}$ levels, though effect estimates at longer lags were in the protective direction (table $3 \Downarrow$ and fig $1 \Downarrow$ ). A $10 \mu \mathrm{g} / \mathrm{m}^{3}$ increase in $\mathrm{PM}_{10}$ level was associated with a $1.2 \%$ (95\% confidence interval $0.3 \%$ to $2.1 \%)$ increase in myocardial infarction risk 1-6 hours later, but in subsequent lag periods the risk was reduced so that over 1-72 hours there was no overall risk increase (cumulative change in risk $-0.8 \%(-1.8 \%$ to $0.2 \%)$ ). Similarly for $\mathrm{NO}_{2}$, a $10 \mu \mathrm{g} / \mathrm{m}^{3}$ increase was associated with a $1.1 \%(0.3 \%$ to $1.8 \%)$ increase in risk 1-6 hours later, but no net risk increase over 72 hours (cumulative change in risk $-0.4 \%(-1.2 \%$ to $0.4 \%)$ ). There was little evidence of any detrimental effect of $\mathrm{CO}$, ozone, or $\mathrm{SO}_{2}$ in single pollutant models; indeed, for $\mathrm{CO}$ the net effects over 1-72 hours were in the protective direction.

In the multi-pollutant model containing all five pollutants, the immediate effect of $\mathrm{NO}_{2}$ persisted, and there remained weak evidence of an independent effect of $\mathrm{PM}_{10}$, though the confidence interval just included the null $(\mathrm{P}=0.05)$ (table $3 \Downarrow)$. After adjustment for other pollutants, there was a suggestion of a positive association between higher ozone levels and myocardial infarction risk at 1-6 hours lag, but this was more than cancelled out over the longer term, with some evidence of a protective association over 72 hours $(-1.2 \%(-2.1 \%$ to $-0.2 \%)$ change in risk per $10 \mu \mathrm{g} / \mathrm{m}^{3}$ increase in ozone). For CO, both the shortest lag effect and the cumulative effect were in the protective direction $(-1.3 \%$ ( $-2.3 \%$ to $-0.2 \%)$ change in risk per $0.1 \mathrm{mg} / \mathrm{m}^{3}$ increase, over 72 hours). Of note, in two pollutant models (web table A in appendix), the appearance of both a detrimental effect of ozone at lag 1-6 hours and an apparently protective association between $\mathrm{CO}$ and myocardial infarction risk at lag 1-6 hours seemed to be driven by adjustment for $\mathrm{NO}_{2}$, with which both ozone and $\mathrm{CO}$ are strongly correlated in opposite directions ( $r=-0.58$ and 0.61 respectively).

\section{Effect modification by age, prior coronary heart disease, and smoking}

For $\mathrm{NO}_{2}$, the pattern of a raised risk of myocardial infarction associated with 1-6 hour lagged pollution levels followed by a reduced risk associated with 7-12 hour lagged levels seemed to be restricted to intermediate age groups, with little evidence of any such pattern in those aged $<60$ or $\geq 80$ years $\left(\mathrm{P}_{\text {interaction }}=0.002\right.$, fig $\left.2 \Downarrow\right)$. A similar pattern was observed visually for $\mathrm{PM}_{10}$, but there was little statistical evidence of effect modification for this or other pollutants after allowing for multiple testing. We found weak evidence that the effects of $\mathrm{NO}_{2}$ were also more pronounced among those with prior coronary heart disease $\left(\mathrm{P}_{\text {interaction }}=0.007\right.$, web fig $\mathrm{A}$ in appendix $)$, but no evidence of any effect modification by smoking status (web fig B, $\mathrm{P}_{\text {interaction }}>0.73$ for each pollutant).

\section{Pollution effects by season and the role of hourly temperature}

Web figure $\mathrm{C}$ shows the associations between pollution and myocardial infarction by season (summer $v$ other seasons). Effect estimates for the short lag effects of $\mathrm{NO}_{2}$ and myocardial infarction risk were larger in the autumn-spring periods compared with summer, whereas we observed the opposite pattern for $\mathrm{PM}_{10}$. However, there was little evidence that these or other variations by season were any greater than expected by chance $\left(\mathrm{P}_{\text {interaction }}>0.33\right.$ for each pollutant). Web figure $\mathrm{D}$ shows the effects of adjusting for hourly (as well as daily) temperature in the nine conurbations where these data were available. Effect estimates were similar before and after adjustment for hourly temperature. 


\section{Sensitivity of pollutant effects to key model specifications}

Our findings seemed robust with regard to (i) restricting analysis to those cases with a recorded time of symptom onset; (ii) restricting to those with corroborative evidence confirming the myocardial infarction diagnosis; (iii) using robust standard errors to allow for any clustering by conurbation; (iv) altering the strategy for selecting control days; (v) matching control days on, rather than adjusting for, day of the week; and (vi) relaxing the assumption of linearity when adjusting for temperature effects. The results of analyses (i) to (iii) are presented in web table B.

For each sensitivity analysis, all confidence intervals included the original effect estimates from our main single pollutant models. For $\mathrm{PM}_{10}$ and $\mathrm{NO}_{2}$, the estimated excess risk associated with a $10 \mu \mathrm{g} / \mathrm{m}^{3}$ increase at lag $1-6$ hours in the six sensitivity analyses ranged from $0.9 \%$ to $1.3 \%$ and from $0.5 \%$ to $1.2 \%$ respectively, compared with our original estimates of $1.2 \%$ (95\% confidence interval $0.3 \%$ to $2.1 \%$ ) and $1.1 \%(0.3 \%$ to $1.8 \%$ ) respectively. The patterns of effects at longer lags and for other pollutants were also consistent across models. As expected, confidence intervals estimated from the sensitivity analyses were generally wider, since the analyses involved the inevitable reduction in power associated with excluding events (analyses i and ii), calculating robust standard errors (analysis iii), and using smaller case-control sets (analyses iv and v).

\section{Discussion}

\section{Principal findings}

Our results from both single and multi-pollutant models suggested that higher ambient levels of $\mathrm{PM}_{10}$ and $\mathrm{NO}_{2}$ were associated with short term increases in myocardial infarction risk 1-6 hours later. $\mathrm{PM}_{10}$ and $\mathrm{NO}_{2}$ are produced in urban areas largely by motor vehicles and are therefore likely to be markers of traffic related pollution. The immediate risk increases were followed by reductions in risk at longer lags, and we found no evidence of a net excess risk associated with any of the five pollutants studied over a 72 hour period after exposure; indeed, for ozone and $\mathrm{CO}$ we observed net protective associations.

\section{Comparison with other studies}

Only a handful of studies have looked at the associations between pollution and myocardial infarction risk at an hourly temporal resolution. A study in Greater Boston estimated an $11 \%(1.5 \%$ to $21.1 \%$ ) increase in myocardial infarction risk $1-3$ hours after a $10 \mu \mathrm{g} / \mathrm{m}^{3}$ increase in $\mathrm{PM}_{10},{ }^{9}$ a larger effect than we have estimated here, though it should be noted that in this small $(n=772)$ study the wide confidence interval would not rule out a more modest true effect. The authors found no convincing effects of ozone, $\mathrm{CO}, \mathrm{NO}_{2}$, or $\mathrm{SO}_{2}$ at a similar 1-3 hour lag. A larger US study found no effects of $\mathrm{PM}_{2.5}, \mathrm{CO}$, or $\mathrm{SO}_{2}$ using various "averaged" lag periods ranging from $0-1$ hour to $0-24$ hours, ${ }^{20}$ but this study did not include $\mathrm{PM}_{10}$ and $\mathrm{NO}_{2}$, for which we found the most consistent short lag effects.

Other studies have looked at various particulate exposures with varied results. Total suspended particulate levels (thought to be equivalent to $\mathrm{PM}_{13}$ ) have been associated with myocardial infarction risk at lags up to 6 hours, ${ }^{21}$ which would be consistent with our findings, but longer lags were not included, so it is not possible to say whether a subsequent reduction in risk over the longer term would have been observed, as in our study. A study in Germany looking at short lag effects of $\mathrm{PM}_{2.5}$ and "total number concentrate" found no associations with myocardial infarction risk at 1 hour lag. ${ }^{22}$ However, results from the same study did suggest a significantly increased risk of myocardial infarction associated with exposure to traffic 1 hour earlier. ${ }^{11}$ Again, longer lags were not included, so it is not possible to say whether there would have been a subsequent reduction in risk.

\section{Implications and possible mechanisms}

The pattern of a positive association between pollutant and myocardial infarction over 1-6 hours but then an inverse association at longer lags is consistent with a short term displacement (or "harvesting") effect of pollution. ${ }^{23}$ For $\mathrm{NO}_{2}$ in particular, the pattern was more prominent among older individuals (with the exception of those aged $\geq 80$ years, which might reflect a greater proportion of time spent indoors in this age group) and those with prior coronary heart

disease-observations that are also consistent with short term displacement since those with a higher baseline risk would be expected to be more vulnerable to the phenomenon. This indicates that one of the pathways through which pollution affects cardiovascular diseases may involve the bringing forward (for example, by a few hours) of events that would have happened anyway.

Since we observed no net increase in myocardial infarction risk over a broader timescale, there may be limited potential for reducing the overall burden of myocardial infarction through reductions in pollution alone, but that should not undermine calls for action on air pollution, which has well established associations with broader health outcomes including overall, respiratory, and cardiovascular mortality. ${ }^{24-26}$ Indeed, air pollution effects on mortality are unlikely to be explained purely by short term displacement. ${ }^{23}$ Our findings might therefore suggest that other, perhaps non-thrombotic, mechanisms are more important drivers of the net mortality increases associated with higher pollution levels.

Several observational and experimental studies suggest pathways through which pollution exposure may trigger myocardial infarction. ${ }^{28}$ Exposure may lead to a systemic inflammatory response,${ }^{29}$ to increased heart rate or decreased heart rate variability, ${ }^{29}{ }^{30}$ to increased blood viscosity or plasma fibrinogen changes, ${ }^{31}{ }^{32}$ or to increased blood pressure. ${ }^{33}$ However, the pollutants we studied are in most cases emitted as part of a complex mixture (in particular emissions caused by traffic exhaust). Individual pollutants cannot be assumed to be causally related to outcomes with which they are associated outside of controlled exposure studies in a laboratory setting, but should instead be considered indicators of the mixture of pollutants with which they are correlated.

This point may also be pertinent to our observations of a net protective association of both ozone and $\mathrm{CO}$ with myocardial infarction risk over 72 hours, which seems implausible as a causal relationship. Negative associations between ozone and myocardial infarction have been observed in other studies, ${ }^{622} 34$ and one theory is that ozone is acting as a marker for one or more unmeasured pollutants (such as methyl nitrites ${ }^{35}$ or $\mathrm{PM}_{2.5}$ ) with which it is inversely correlated and which have positive associations with myocardial infarction risk. Another possibility is that collinearities between the model covariates are responsible ${ }^{36}$ : correlations between pollutant pairs of up to 0.61 suggest that caution should be applied in interpreting the independent effect estimates, particularly for $\mathrm{CO}$ and ozone in models adjusted for $\mathrm{NO}_{2}$, with which both pollutants were strongly correlated. 


\section{Strengths and limitations of the study}

Our study has some limitations: First, we did not have sufficient data to include $\mathrm{PM}_{2.5}$ in our analyses, and this may be an important predictor of myocardial infarction risk $;{ }^{8}$ however, in the one monitoring station where both measures were recorded the correlation was high (0.92), so we believe that including $\mathrm{PM}_{10}$ in our models should have accounted for any major confounding effects of finer particulates. Second, we used pollution measures from fixed outdoor monitors which will not perfectly represent fluctuations in personal exposure, particularly where there is any marked geographical variability in pollutant levels. Restricting analysis to urban areas should have reduced heterogeneity in the pollutant levels to which study populations were exposed, and data from fixed location monitors have been found to be a reasonable proxy for personal exposure to particulate matter. ${ }^{37}$ Nevertheless the use of ambient pollution levels averaged over a conurbation is likely to have resulted in some degree of "measurement error". As long as the true personal exposures, averaged across the population, can be assumed to fluctuate in step with measured ambient levels, no bias would have been introduced, though some precision would have been lost. In reality this assumption is unlikely to hold perfectly, and measurement errors may therefore have resulted in some bias towards the null for single pollutant models, or in either direction for multi-pollutant models. ${ }^{38}$ Third, power and precision may have been reduced by adjusting analyses for covariates (such as temperature) likely to be correlated with exposure, though a trade off must be made here: such adjustment is necessary to avoid confounded estimates. Fourth, we used hospital admissions data which would have excluded myocardial infarctions resulting in death before hospital admission; if pollution level increases were associated with particularly severe and rapidly fatal myocardial infarctions, such effects might have been missed. Finally, given the limited prior evidence available at an hourly temporal resolution, our study did not test specific prior hypotheses, but rather explored a number of possible pollution-myocardial infarction associations on this timescale; future studies testing the specific associations we have observed will be needed to confirm our conclusions and rule out that our findings were due to chance.

Despite these limitations, to our knowledge our study is the largest to date to investigate associations between the commonly measured pollutants and myocardial infarction risk at an hourly temporal resolution, adjusting for key confounders. MINAP has comprehensive coverage and does not restrict on demographic criteria, so hospital admissions recorded should be representative of those occurring within the locations under study; myocardial infarction diagnoses in MINAP are also likely to be highly specific and our results were confirmed in a sensitivity analysis using only events that could be validated using ECG and/or laboratory marker data, as well as in a number of further sensitivity analyses.

\section{Conclusions}

We estimated that higher ambient levels of the traffic associated pollutants $\mathrm{PM}_{10}$ and $\mathrm{NO}_{2}$ were followed by a transiently increased risk of myocardial infarction up to 6 hours later. There appeared to be subsequent reductions in risk at longer lags, consistent with a short term displacement or harvesting effect. Numerous studies have demonstrated that higher levels of air pollution are associated with increased cardiorespiratory mortality. In urban settings in England and Wales, we did not find a similar association with the overall acute risk of myocardial infarction specifically, suggesting that these established mortality effects may be mediated through other mechanisms.

Contributors: KB, SH, BA, AH, PW, and LS were involved in the design of the study. $\mathrm{KB}$ and $\mathrm{EH}$ prepared and cleaned the data. $\mathrm{KB}$ did the statistical analysis and wrote the first draft. $\mathrm{SH}, \mathrm{BA} \mathrm{AH}, \mathrm{EH}, \mathrm{PW}$, and LS contributed to further drafts. KB and LS are the guarantors for the study; KB had full access to all of the data in the study and takes responsibility for the integrity of the data and the accuracy of the data analysis.

Funding: This work was supported by the British Heart Foundation (grant number FS/04/045) and the Garfield Weston Foundation. LS is supported by a Wellcome Trust Senior Research Fellowship in Clinical Science (grant number 082178). SH is funded by a Wellcome Trust Research Career Development Fellowship (grant number 076583/Z/05/Z). The funding bodies had no role in the design or conduct of this study or in the preparation, review, approval, or decision to submit the manuscript. All authors carried out this research independently of the funding bodies. Competing interests: All authors have completed the unified competing interest form at www.icmje.org/coi_disclosure.pdf (available on request from the corresponding author) and declare: KB, EH, and LS had support for the submitted work from the British Heart Foundation, the Garfield Weston Trust, and the Wellcome Trust respectively; no financial relationships with any organisations that might have an interest in the submitted work in the previous three years; no other relationships or activities that could appear to have influenced the submitted work

Ethical approval: The study was approved by the London School of Hygiene and Tropical Medicine Ethics Committee (application number 5218).

Data sharing: No additional data available.

Dockery DW, Pope CA 3rd, Xu X, Spengler JD, Ware JH, Fay ME, et al. An association between air pollution and mortality in six U.S. cities. N Engl J Med 1993;329:1753-9.

2 Katsouyanni K, Touloumi G, Spix C, Schwartz J, Balducci F, Medina S, et al. Short-term effects of ambient sulphur dioxide and particulate matter on mortality in 12 European cities: results from time series data from the APHEA project. Air Pollution and Health: a European Approach. BMJ 1997;314:1658-63.

3 Pope CA 3rd, Schwartz J, Ransom MR. Daily mortality and PM10 pollution in Utah Valley. Arch Environ Health 1992;47:211-7.

4 Pope CA 3rd, Thun MJ, Namboodiri MM, Dockery DW, Evans JS, Speizer FE, et al. Particulate air pollution as a predictor of mortality in a prospective study of US adults. $A m$ J Respir Crit Care Med 1995;151:669-74.

5 Maheswaran R, Haining RP, Brindley P, Law J, Pearson T, Fryers PR, et al. Outdoor air pollution, mortality, and hospital admissions from coronary heart disease in Sheffield, UK: a small-area level ecological study. Eur Heart J 2005;26:2543-9.

6 Mann JK, Tager IB, Lurmann F, Segal M, Quesenberry CP Jr, Lugg MM, et al. Air pollution and hospital admissions for ischemic heart disease in persons with congestive heart failure or arrhythmia. Environ Health Perspect 2002;110:1247-52.

7 Samet JM, Dominici F, Curriero FC, Coursac I, Zeger SL. Fine particulate air pollution and mortality in 20 US cities, 1987-1994. N Engl J Med 2000;343:1742-9.

8 Bhaskaran K, Hajat S, Haines A, Herrett E, Wilkinson P, Smeeth L. Effects of air pollution on the incidence of myocardial infarction. Heart 2009;95:1746-59.

9 Peters A, Dockery DW, Muller JE, Mittleman MA. Increased particulate air pollution and the triggering of myocardial infarction. Circulation 2001;103:2810-5.

10 Burgan O, Smargiassi A, Perron S, Kosatsky T. Cardiovascular effects of sub-daily levels of ambient fine particles: a systematic review. Environ Health 2010;9:26.

11 Peters A, von Klot S, Heier M, Trentinaglia I, Hormann A, Wichmann HE, et al. Exposure to traffic and the onset of myocardial infarction. [see comment] $N$ Engl J Med 2004;351:1721-30.

12 Mills NL, Törnqvist H, Gonzalez MC, Vink E, Robinson SD, Söderberg S, et al. Ischemic and thrombotic effects of dilute diesel-exhaust inhalation in men with coronary heart disease. N Engl J Med 2007;357:1075-82.

13 Doherty RM, Hearl MR, Wilkinson P, Pattenden S, Vieno M, Armstrong B, et al. Current and future climate- and air pollution-mediated impacts on human health. Environ Health 2009;8(suppl 1):S8.

14 Ruckerl R, Greven S, Ljungman P, Aalto P, Antoniades C, Bellander T, et al. Air pollution and inflammation (interleukin-6, C-reactive protein, fibrinogen) in myocardial infarction survivors. Environ Health Perspect 2007;115:1072-80.

15 Lumley T, Levy D. Bias in the case-crossover design: implications for studies of air pollution. Environmetrics 2000;11:689-704.

16 Janes H, Sheppard L, Lumley T. Case-crossover analyses of air pollution exposure data: referent selection strategies and their implications for bias. Epidemiology 2005;16:717-26.

17 Bhaskaran K, Hajat S, Haines A, Herrett E, Wilkinson P, Smeeth L. Short term effects of temperature on risk of myocardial infarction in England and Wales: time series regression analysis of the Myocardial Ischaemia National Audit Project (MINAP) registry. BMJ 2010;341:c3823

18 Woolhiser DA, Pegram GGS. Maximum likelihood estimation of Fourier coefficients to describe seasonal variation of parameters in stochastic daily precipitation models. J Appl Meteor 1979;18:34-42. 


\section{What is already known on this topic}

Higher daily levels of some pollutants are associated with increased mortality

There is mixed evidence on the effects of pollution on risk of myocardial infarction specifically

A few studies with hourly data have found pollution effects just a few hours after exposure

\section{What this study adds}

Myocardial infarction risk was transiently increased up to 6 hours after exposure to higher levels of the traffic associated pollutants $\mathrm{PM}_{10}$ and $\mathrm{NO}_{2}$

Pollution effects were consistent with short term displacement of events ("harvesting"), but none of the pollutants investigated seemed to be associated with an increase in overall myocardial infarction risk over 72 hours

The well established effect of air pollution on cardiorespiratory mortality may not be mediated through increasing the acute risk of myocardial infarction, but through another mechanism

19 Armstrong B. Models for the relationship between ambient temperature and daily mortality. Epidemiology 2006;17:624-31.

20 Sullivan J. Relation between short-term fine-particulate matter exposure and onset of myocardial infarction. [see comment] Epidemiology 2005;16:41-8.

21 Murakami $Y$, Ono M. Myocardial infarction deaths after high level exposure to particulate matter. J Epidemiol Community Health 2006;60:262-6.

22 Peters A, von Klot S, Heier M, Trentinaglia I, Cyrys J, Hormann A, et al. Particulate air pollution and nonfatal cardiac events. Part I. Air pollution, personal activities, and onset of myocardial infarction in a case-crossover study. Res Rep Health Eff Inst 2005;(124):1-66; discussion 67-82, 141-8.

23 Schwartz J. Is there harvesting in the association of airborne particles with daily deaths and hospital admissions? Epidemiology 2001;12:55-61.

24 Committee on the Medical Effects of Air Pollutants. Cardiovascular disease and air pollution Department of Health, 2006

25 Miller KA, Siscovick DS, Sheppard L, Shepherd K, Sullivan JH, Anderson GL, et al. Long-term exposure to air pollution and incidence of cardiovascular events in women.[see comment] N Engl J Med 2007;356:447-58.

26 Smith KR, Jerrett M, Anderson HR, Burnett R, Stone V, Derwent R, et al. Public health benefits of strategies to reduce greenhouse-gas emissions: health implications of short-lived greenhouse pollutants. Lancet 2009;374:2091-103.

27 Zeger SL, Dominici F, Samet J. Harvesting-resistant estimates of air pollution effects on mortality. Epidemiology 1999;10:171-5.

28 Bhaskaran K, Wilkinson P, Smeeth L. Cardiovascular consequences of air pollution: what are the mechanisms? Heart 2011;97:519-20.

29 Pope CA 3rd, Hansen ML, Long RW, Nielsen KR, Eatough NL, Wilson WE, et al. Ambient particulate air pollution, heart rate variability, and blood markers of inflammation in a panel of elderly subjects. Environ Health Perspect 2004;112:339-45.

30 Pope CA 3rd, Verrier RL, Lovett EG, Larson AC, Raizenne ME, Kanner RE, et al. Heart rate variability associated with particulate air pollution. Am Heart $J$ 1999;138:890-9.

31 Ghio AJ, Kim C, Devlin RB. Concentrated ambient air particles induce mild pulmonary inflammation in healthy human volunteers. Am J Respir Crit Care Med 2000;162:981-8.
32 Peters A, Doring A, Wichmann HE, Koenig W. Increased plasma viscosity during an air pollution episode: a link to mortality? Lancet 1997;349:1582-7.

33 Zanobetti A, Canner MJ, Stone PH, Schwartz J, Sher D, Eagan-Bengston E, et al. Ambient pollution and blood pressure in cardiac rehabilitation patients. Circulation 2004;110:2184-9.

34 Koken PJM, Piver WT, Ye F, Elixhauser A, Olsen LM, Portier CJ. Temperature, air pollution, and hospitalization for cardiovascular diseases among elderly people in Denver. Environ Health Perspect 2003;111:1312-7.

35 Joseph PM. Paradoxical ozone associations could be due to methyl nitrite from combustion of methyl ethers or esters in engine fuels. Environ Int 2007;33:1090-106.

36 Dominici F, Peng RD, Barr CD, Bell ML. Protecting human health from air pollution: shifting from a single-pollutant to a multipollutant approach. Epidemiology 2010;21:187-94.

37 Janssen NA, de Hartog JJ, Hoek G, Brunekreef B, Lanki T, Timonen KL, et al. Personal exposure to fine particulate matter in elderly subjects: relation between personal, indoor, and outdoor concentrations. J Air Waste Manag Assoc 2000;50:1133-43.

38 Zeger SL, Thomas D, Dominici F, Samet JM, Schwartz J, Dockery D, et al. Exposure measurement error in time-series studies of air pollution: concepts and consequences Environ Health Perspect 2000;108:419-26.

39 Bland JM, Altman DG. Calculating correlation coefficients with repeated observations: Part 1-Correlation within subjects. BMJ 1995;310:446.

\section{Accepted: 04 August 2011}

\section{Cite this as: BMJ 2011;343:d5531}

This is an open-access article distributed under the terms of the Creative Commons Attribution Non-commercial License, which permits use, distribution, and reproduction in any medium, provided the original work is properly cited, the use is non commercial and is otherwise in compliance with the license. See: http://creativecommons.org/licenses/by$\mathrm{nc} / 2.0 /$ and http://creativecommons.org/licenses/by-nc/2.0/legalcode. 


\section{Tables}

Table 1/ Characteristics of myocardial infarctions and local levels of air pollutants in 15 conurbations in England and Wales. Values are medians (interquartile range) unless stated otherwise

\begin{tabular}{|c|c|c|c|c|c|c|c|c|c|c|}
\hline \multirow[b]{2}{*}{ Conurbation } & \multicolumn{2}{|c|}{ Myocardial infarction } & \multirow[b]{2}{*}{ No (\%) male* } & \multirow[b]{2}{*}{$\begin{array}{c}\text { Age } \\
(\text { years })^{*}\end{array}$} & \multirow{2}{*}{$\begin{array}{l}\text { No (\%) with } \\
\text { supporting } \\
\text { evidence† }\end{array}$} & \multicolumn{5}{|c|}{ Hourly pollution levels $\left(\mu \mathrm{g} / \mathrm{m}^{3}\right.$, except $\left.\mathrm{CO}\left(\mathrm{mg} / \mathrm{m}^{3}\right)\right)$} \\
\hline & Total No & $\begin{array}{l}\text { No (\%) with } \\
\text { ST elevation }\end{array}$ & & & & $\mathrm{PM}_{10}$ & Ozone & $\mathrm{co}$ & $\mathrm{NO}_{2}$ & $\mathrm{SO}_{2}$ \\
\hline Bristol & 1879 & $668(36)$ & $1203 / 1860(65)$ & $72(61-81)$ & $1765(95)$ & $22(16-31)$ & $42(20-60)$ & $0.5(0.3-0.8)$ & $47(29-67)$ & $3(3-5)$ \\
\hline Cardiff & 1466 & $507(35)$ & $855 / 1459(59)$ & $75(63-83)$ & $1441(99)$ & $25(17-34)$ & $42(20-58)$ & $0.2(0.2-0.3)$ & $29(19-44)$ & $3(0-3)$ \\
\hline Greater London & 26202 & $11963(46)$ & $\begin{array}{c}17600 / 26129 \\
(67)\end{array}$ & $70(58-79)$ & $22973(88)$ & $27(20-36)$ & $32(14-50)$ & $0.4(0.3-0.6)$ & $50(38-65)$ & $4(3-6)$ \\
\hline $\begin{array}{l}\text { Greater } \\
\text { Manchester }\end{array}$ & 11680 & $4970(43)$ & $\begin{array}{c}7255 / 11670 \\
(62)\end{array}$ & 1) & 36) & ) & ) & ) & )) & $7(5-10)$ \\
\hline Kingston-on-Hull & 368 & $330(90)$ & $248 / 367(68)$ & $65(57-74)$ & $360(98)$ & $21(14-31)$ & $44(24-62)$ & $0.1(0.1-0.2)$ & $23(13-38)$ & $3(3-8)$ \\
\hline Leicester & 1744 & $957(55)$ & $1227 / 1744(70)$ & $69(57-78)$ & $1672(96)$ & $20(14-27)$ & $38(16-56)$ & $0.2(0.2-0.5)$ & $31(19-46)$ & $3(0-5)$ \\
\hline Liverpool & 3860 & $1429(37)$ & $2322 / 3857$ (60) & $73(62-81)$ & $3293(85)$ & $20(13-27)$ & $50(30-66)$ & $0.1(0.1-0.2)$ & 19 (10-32) & $5(3-8)$ \\
\hline Norwich & 846 & $326(39)$ & $590 / 846(70)$ & $70(60-78)$ & 841 (99) & $18(13-26)$ & $42(22-62)$ & $0.2(0.2-0.3)$ & $23(14-36)$ & $11(3-16)$ \\
\hline Nottingham & 1481 & $903(61)$ & $969 / 1469(66)$ & $68(57-78)$ & $1357(92)$ & $21(14-30)$ & $32(14-50)$ & $0.3(0.2-0.5)$ & $32(21-46)$ & $11(3-16)$ \\
\hline Potteries & 2186 & $850(39)$ & $1423 / 2186(65)$ & $72(60-81)$ & $1697(78)$ & $22(14-30)$ & $44(24-60)$ & $0.3(0.2-0.6)$ & $29(17-42)$ & $8(5-13)$ \\
\hline Sheffield & 3107 & $1305(42)$ & $1913 / 3086(62)$ & $71(60-81)$ & 3025 (98) & $21(13-31)$ & $32(15-49)$ & $0.3(0.2-0.5)$ & $34(23-47)$ & $10(6-12)$ \\
\hline Southampton & 1259 & $517(41)$ & $875 / 1259(69)$ & 69 (58-79) & $1248(99)$ & $23(17-33)$ & $36(16-52)$ & $0.2(0.2-0.5)$ & $29(19-42)$ & $3(3-5)$ \\
\hline Tyneside & 8000 & $2406(30)$ & $4691 / 7993$ (59) & $73(61-81)$ & $6697(84)$ & $16(10-23)$ & $42(24-60)$ & $0.1(0.1-0.2)$ & $27(15-40)$ & $3(3-5)$ \\
\hline West Midlands & 8693 & $4788(55)$ & $5872 / 8674(68)$ & $69(58-78)$ & $8272(95)$ & $20(15-29)$ & $41(23-59)$ & $0.3(0.2-0.4)$ & $29(19-44)$ & $3(2-5)$ \\
\hline West Yorkshire & 6517 & $2647(41)$ & $3945 / 6119(64)$ & $69(58-77)$ & 5687 (93) & $23(16-34)$ & $36(18-52)$ & $0.3(0.2-0.6)$ & $31(19-46)$ & $7(6-10)$ \\
\hline Overall & 79288 & 34566 (44) & $\begin{array}{c}50988 / 78718 \\
(64)\end{array}$ & $70(59-80)$ & 70331 (89) & $21(14-30)$ & $38(19-56)$ & $0.3(0.2-0.5)$ & $31(19-47)$ & $5(3-9)$ \\
\hline
\end{tabular}

*Data on age available for $81441 / 84010$ (97\%) of diagnoses, and data on sex available for $83424 / 84010$ (99\%) of diagnoses.

†For ST elevation myocardial infarction, evidence was defined as either an electrocardiogram indicating ST elevation or left bundle branch block, or raised markers (troponin or creatine kinase). For non-ST elevation myocardial infarction, evidence was defined as raised markers only. 
Table 2/ Correlation coefficients between exposure variables (temperature and air pollutants) measured in 15 conurbations in England and Wales. Values are overall correlations (correlations for summer*/other seasons)

\begin{tabular}{|c|c|c|c|c|c|c|}
\hline & Temperature $†$ & $\mathrm{PM}_{10}$ & Ozone & $\mathrm{co}$ & $\mathrm{NO}_{2}$ & $\mathrm{SO}_{2}$ \\
\hline Temperature & 1.00 & - & - & - & - & - \\
\hline $\mathrm{PM}_{10}$ & $0.04(0.37 / 0.02)$ & 1.00 & - & - & - & - \\
\hline Ozone & $0.38(0.56 / 0.31)$ & $-0.15(0.21 /-0.26)$ & 1.00 & - & - & - \\
\hline $\mathrm{CO}$ & $-0.24(0.13 /-0.23)$ & $0.4(0.23 / 0.44)$ & $-0.37(-0.06 /-0.42)$ & 1.00 & - & - \\
\hline $\mathrm{NO}_{2}$ & $-0.25(0.17 /-0.22)$ & $0.48(0.43 / 0.49)$ & $-0.58(-0.23 /-0.66)$ & $0.61(0.45 / 0.62)$ & 1.00 & - \\
\hline $\mathrm{SO}_{2}$ & $-0.03(0.17 /-0.04)$ & $0.26(0.21 / 0.28)$ & $-0.14(0.02 /-0.18)$ & $0.30(0.23 / 0.31)$ & $0.31(0.27 / 0.32)$ & 1.00 \\
\hline
\end{tabular}

*Summer defined as the months of June, July, and August.

†Correlations with temperature based on the nine conurbations with hourly temperature data.

Within-conurbation correlation coefficients were estimated from regression models adjusted for conurbation, ${ }^{39}$ and were based on exposure data at an hourly resolution. 


\begin{tabular}{|c|c|c|}
\hline \multirow[b]{2}{*}{ Pollutant and time lag (hours) } & \multicolumn{2}{|c|}{$\%$ excess risk $(95 \% \mathrm{Cl})$ per unit increase $†$} \\
\hline & Single pollutant model & Multi-pollutant model \\
\hline \multicolumn{3}{|l|}{$\mathrm{PM}_{10}:$} \\
\hline $1-6$ & $1.2(0.3$ to 2.1$)$ & $1.0(-0.0$ to 2.0$)$ \\
\hline $7-12$ & $-0.7(-1.7$ to 0.3$)$ & $-0.2(-1.4$ to 1.0$)$ \\
\hline $13-18$ & $-0.3(-1.4$ to 0.7$)$ & $-0.3(-1.5$ to 0.9$)$ \\
\hline $19-24$ & $-0.2(-1.1$ to 0.7$)$ & $-0.2(-1.3$ to 0.8$)$ \\
\hline $25-72$ & $-0.8(-1.8$ to 0.2$)$ & $-0.4(-1.8$ to 1.0$)$ \\
\hline Sum $(1-72) \ddagger$ & $-0.8(-1.8$ to 0.2$)$ & $-0.2(-1.7$ to 1.3$)$ \\
\hline \multicolumn{3}{|l|}{ Ozone: } \\
\hline $1-6$ & $-0.2(-0.8$ to 0.4$)$ & $0.7(-0.1$ to 1.6$)$ \\
\hline $7-12$ & $0.4(-0.3$ to 1.2$)$ & $-0.5(-1.5$ to 0.6$)$ \\
\hline $13-18$ & $-0.6(-1.3$ to 0.1$)$ & $-0.7(-1.8$ to 0.4$)$ \\
\hline $19-24$ & $-0.1(-0.7$ to 0.5$)$ & $-0.2(-1.0$ to 0.7$)$ \\
\hline $25-72$ & $-0.2(-0.9$ to 0.4$)$ & $-0.6(-1.5$ to 0.3$)$ \\
\hline Sum $(1-72) \ddagger$ & $-0.6(-1.3$ to 0.1$)$ & $-1.2(-2.1$ to -0.2$)$ \\
\hline \multicolumn{3}{|l|}{ co: } \\
\hline $1-6$ & $0.2(-0.3$ to 0.7$)$ & $-0.7(-1.4$ to 0.1$)$ \\
\hline $7-12$ & $0.1(-0.6$ to 0.7$)$ & $0.7(-0.2$ to 1.5$)$ \\
\hline $13-18$ & $-0.3(-0.9$ to 0.3$)$ & $0.0(-0.9$ to 0.8$)$ \\
\hline $19-24$ & $-0.2(-0.7$ to 0.4$)$ & $-0.4(-1.1$ to 0.4$)$ \\
\hline $25-72$ & $-0.6(-1.2$ to 0.1$)$ & $-0.8(-1.8$ to 0.2$)$ \\
\hline Sum (1-72) $\ddagger$ & $-0.8(-1.4$ to -0.1$)$ & $-1.3(-2.3$ to -0.2$)$ \\
\hline \multicolumn{3}{|l|}{$\mathrm{NO}_{2}:$} \\
\hline $1-6$ & 1.1 (0.3 to 1.8$)$ & 2.0 (0.8 to 3.3 ) \\
\hline $7-12$ & $-0.9(-1.8$ to -0.1$)$ & $-1.7(-3.2$ to -0.2$)$ \\
\hline $13-18$ & $-0.1(-1.0$ to 0.8$)$ & $-0.6(-2.1$ to 0.9$)$ \\
\hline $19-24$ & $0.0(-0.7$ to 0.8$)$ & $0.2(-1.1$ to 1.5$)$ \\
\hline $25-72$ & $-0.5(-1.3$ to 0.3$)$ & $-0.1(-1.6$ to 1.4$)$ \\
\hline Sum (1-72) $\ddagger$ & $-0.4(-1.2$ to 0.4$)$ & $-0.2(-1.8$ to 1.4$)$ \\
\hline \multicolumn{3}{|l|}{$\mathrm{SO}_{2}:$} \\
\hline $1-6$ & $0.0(-2.2$ to 2.3$)$ & $-0.8(-3.2$ to 1.7$)$ \\
\hline $7-12$ & $0.2(-2.3$ to 2.8$)$ & $0.3(-2.5$ to 3.2$)$ \\
\hline 13-18 & $-1.5(-3.9$ to 1.0$)$ & $-1.2(-3.9$ to 1.5$)$ \\
\hline $19-24$ & $1.6(-0.6$ to 3.9$)$ & $1.8(-0.7$ to 4.3$)$ \\
\hline $25-72$ & $-0.8(-3.7$ to 2.3$)$ & $1.4(-2.3$ to 5.3$)$ \\
\hline Sum $(1-72) \ddagger$ & $-0.4(-3.6$ to 2.9$)$ & $1.4(-2.8$ to 5.8$)$ \\
\hline
\end{tabular}

*Models included the presented pollutant effects and were adjusted for temperature (five lag terms covering days 0-28 inclusive), relative humidity (average of lags 0-3 days), day of week, circulating levels of influenza and respiratory syncytial virus, and residual seasonality within calendar month strata (single sine-cosine pair per conurbation).

†Unit increase is $10 \mu \mathrm{g} / \mathrm{m}^{3}$ for $\mathrm{PM}_{10}$, ozone, $\mathrm{NO}_{2}$, and $\mathrm{SO}_{2}$ and $0.1 \mathrm{mg} / \mathrm{m}^{3}$ for $\mathrm{CO}$.

‡Represents the cumulative effect over lag 1-72 hours, estimated by summing regression coefficients for the five lag terms. 


\section{Figures}
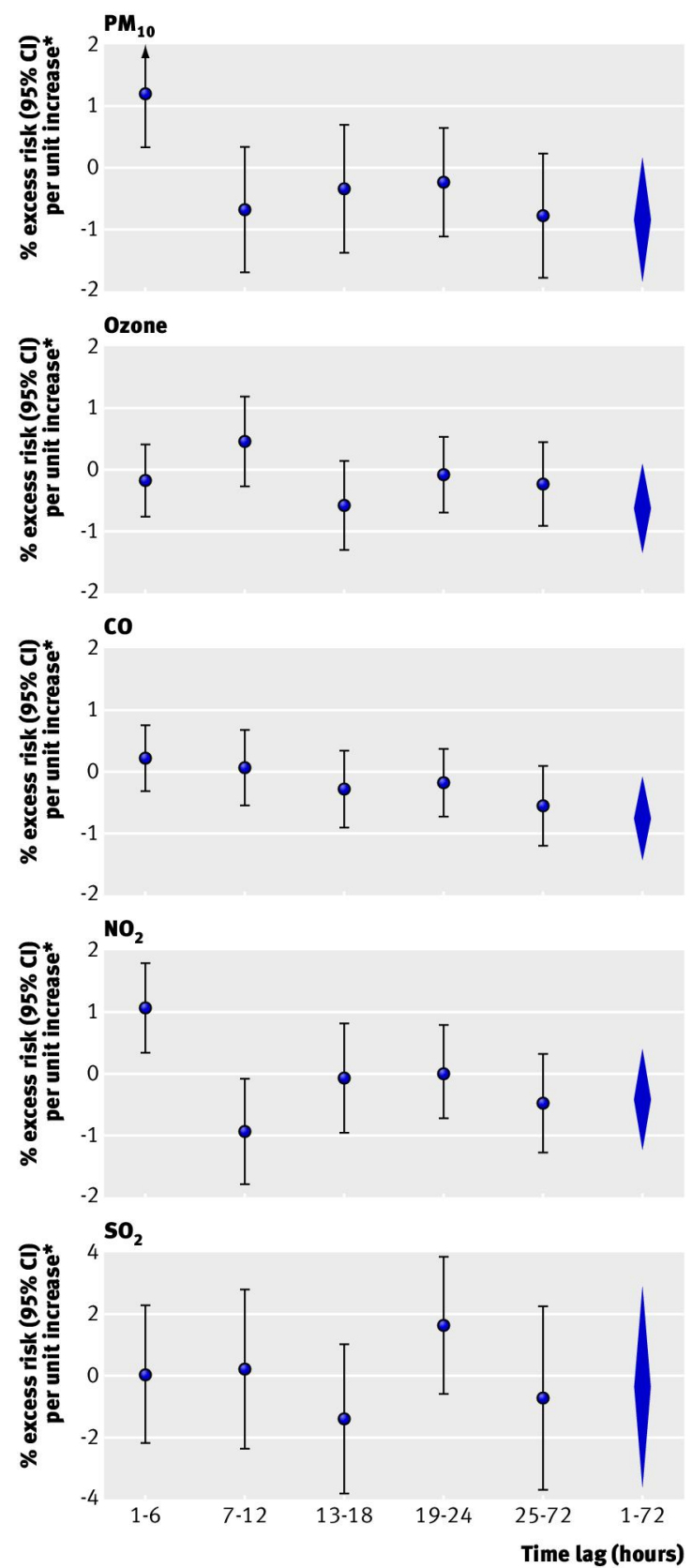

*Unit increase is $10 \mu \mathrm{g} / \mathrm{m}^{3}$ for $\mathrm{PM}_{10}$, ozone, $\mathrm{NO}_{2}$, and $\mathrm{SO}_{2}$ and $0.1 \mathrm{mg} / \mathrm{m}^{3}$ for $\mathrm{CO}$

Fig 1 Estimated excess risk of myocardial infarction associated with increases in air pollutants (with five lag terms covering 0-72 hours) from a single pollutant model (separate models for each of the pollutants adjusted for temperature (five lag terms covering days 0-28 inclusive), relative humidity (average of lags 0-3 days), day of week, circulating levels of influenza and respiratory syncytial virus, and residual seasonality within calendar month strata (single sine-cosine pair per conurbation)). The cumulative effect over lag 1-72 hours for each pollutant is estimated by summing (on the log scale) regression coefficients for the five lag terms 

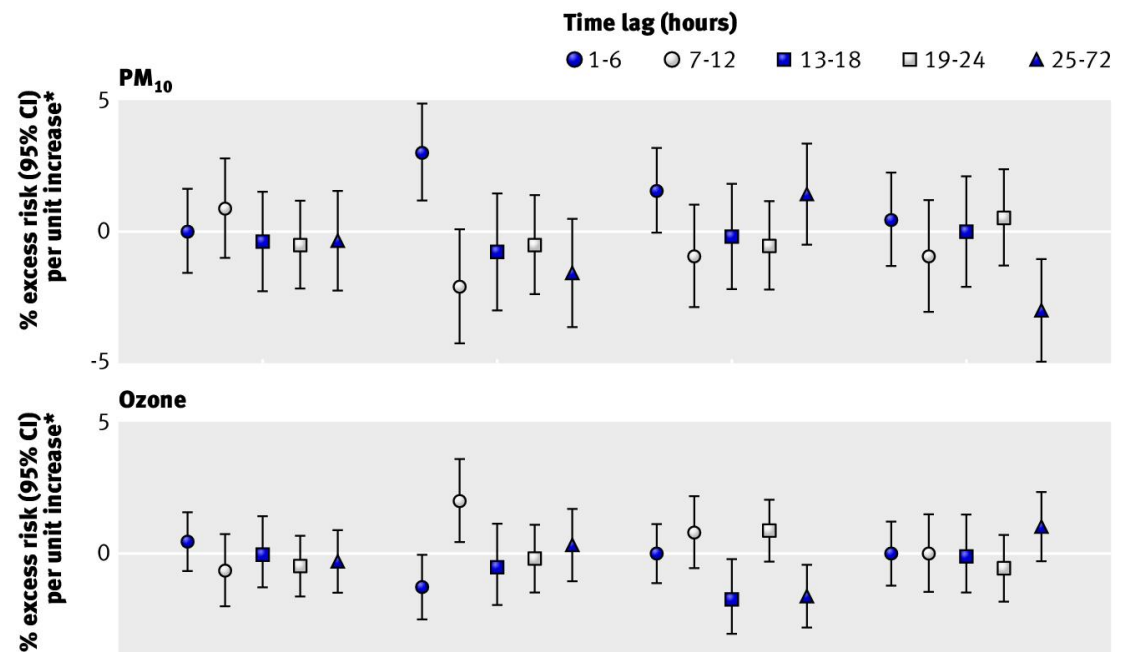

$-5$
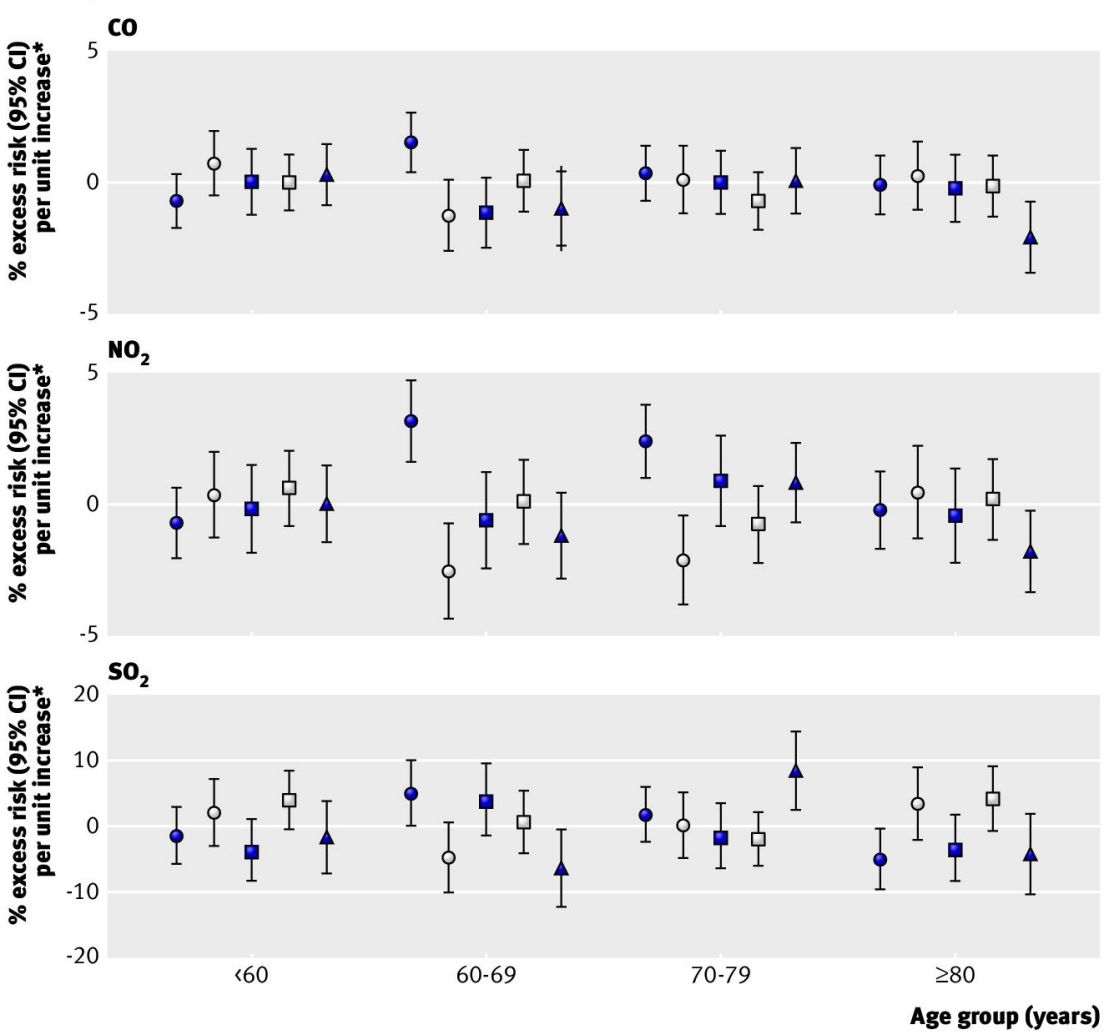

*Unit increase is $10 \mu \mathrm{g} / \mathrm{m}^{3}$ for $\mathrm{PM}_{10}$, ozone, $\mathrm{NO}_{2}$, and $\mathrm{SO}_{2}$ and $0.1 \mathrm{mg} / \mathrm{m}^{3}$ for $\mathrm{CO}$

Fig 2 Estimated excess risk of myocardial infarction associated with increases in air pollutants (with five lag terms covering 0-72 hours) from a single pollutant model (see fig 1 for details) stratified by age group. $P_{\text {interaction }}=0.05,0.54,0.17,0.002$, 0.01 for $\mathrm{PM}_{10}$, ozone, $\mathrm{CO}, \mathrm{NO}_{2}$, and $\mathrm{SO}_{2}$ respectively 